\section{$\because \mathrm{BRC}$}

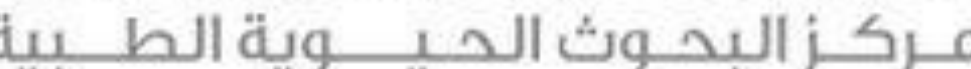

Graduate Students

Medical, Biomedical and Health Sciences

\title{
PAMAM Dendrimers as Anti-HER2 Positive Breast Cancer Treatments
}

\section{INTRODUCTION}

- Poly (amidoamine) dendrimers (PAMAMs) are widely used in drug delivery systems and gene transfection as drug carriers.

- They also exert several biological effects like modulating gene expression, particularly EGFR (ErbB1) signaling pathway, which raises the question of whether these polymers can also inhibit the phosphorylation of HER2 (ErbB2) in breast cancer.

- However, this area hasn't been investigated before.

\section{MATERIALS \& METHODS}

- In this study, we evaluated the anticancer effects of different generations and surface chemistries of PAMAMs on HER2 positive breast cancer cells (SK-BR3). HNME cell were used as a control.

- Cell viability and morphological changes were evaluated upon treatment with PAMAMs.

- Also, their effect on colony formation in soft agar was assessed.

Additionally, western blot was performed to understand the underlying mechanisms of action.

RESULTS

\section{Cell viability}

- SK-BR3 and HNME cells were treated with different concentrations of PAMAM dendrimers for several time intervals (24, 48, and 72 hours).

Amino-terminated PAMAMs at higher generation (G6) had the most significant effect in inhibiting cell viability among both cell lines $(P<0.001)$. This effect was dose-dependent, as they reduced cell viability up to $1.94 \pm 2.14$ and $5.06 \pm$ 2.74 in SK-BR3 and HNME cells, respectively.

Other types of PAMAMs were used at higher doses to produce such inhibition $(P<0.05)$ Figure 1.

PAMAMs reduction of viability was also time-dependent with the highest effect after 72 hours $(P<0.001)$ Figure 2.

\section{Morphological changes}

- The morphological changes were the most significant following the treatment with $\mathrm{G}_{6} \mathrm{NH}_{2}$ PAMAMs, as cells lost their shape, cellular membrane integrity, and cell-cell adhesion compared to controls Figure 3.

- In addition, $\mathrm{G}_{4} \mathrm{NH}_{2}$ PAMAMs induced morphological changes to a less extent only in HNME cells.

- The other types of PAMAMs did not induce a noticeable effect on cell morphology.

\section{Colony formation assay}

Upon treatment with PAMAMs for three weeks, SK-BR3 cells produced a smaller number of colonies in wells treated with $\mathrm{G}_{6} \mathrm{NH}_{2}$ PAMAMs compared to controls, followed by wells treated with $\mathrm{G}_{4} \mathrm{NH}_{2}$ PAMAMs $(P<0.001)$ as shown in Figure 4.

- Colonies size was significantly lower in wells treated with cationic polymers, while colonies in wells treated with $\mathrm{G}_{6} \mathrm{OH}$ and G5.5COOH PAMAMs didn't differ significantly from controls in terms of number and size $(P>0.05)$.

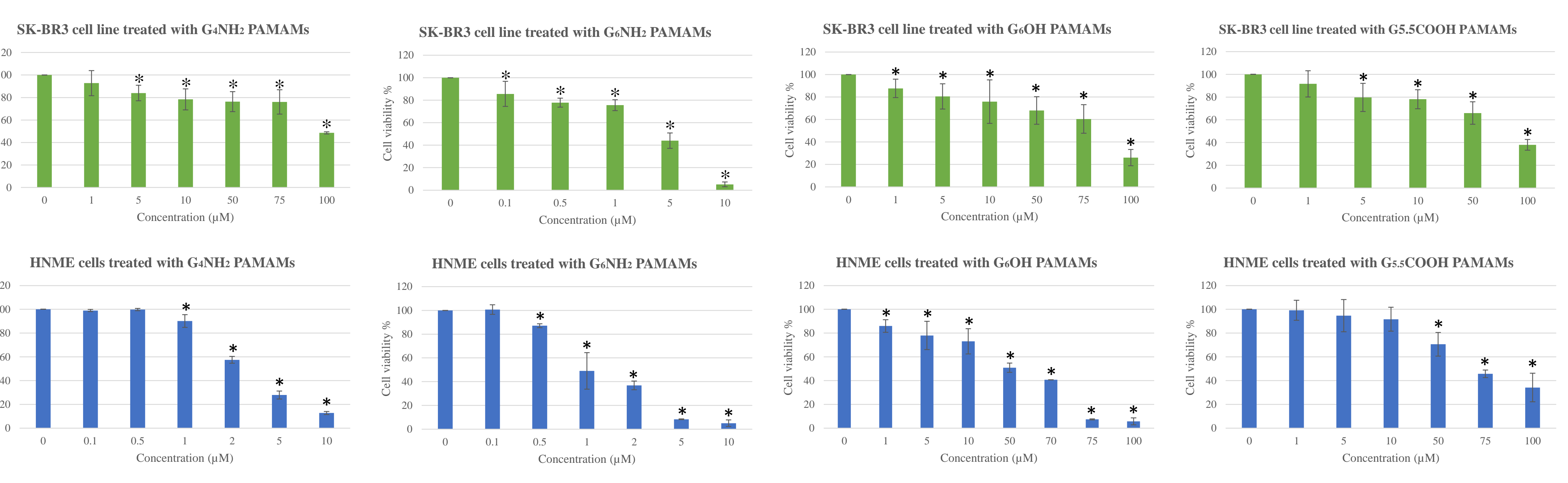

Figure 1: Effects of different doses of PAMAM dendrimers on the viability of SK-BR3 and HNME cells $\mathrm{G}_{4} \mathrm{NH}_{2}: 1$ to $100 \mu \mathrm{M}, \mathrm{G}_{6} \mathrm{NH}_{2}: 0.1$ to $10 \mu \mathrm{M}, \mathrm{G}_{6} \mathrm{OH}: 10$ to $100 \mu \mathrm{M}$, and G5.5COOH: 10 to $100 \mu \mathrm{M}$.

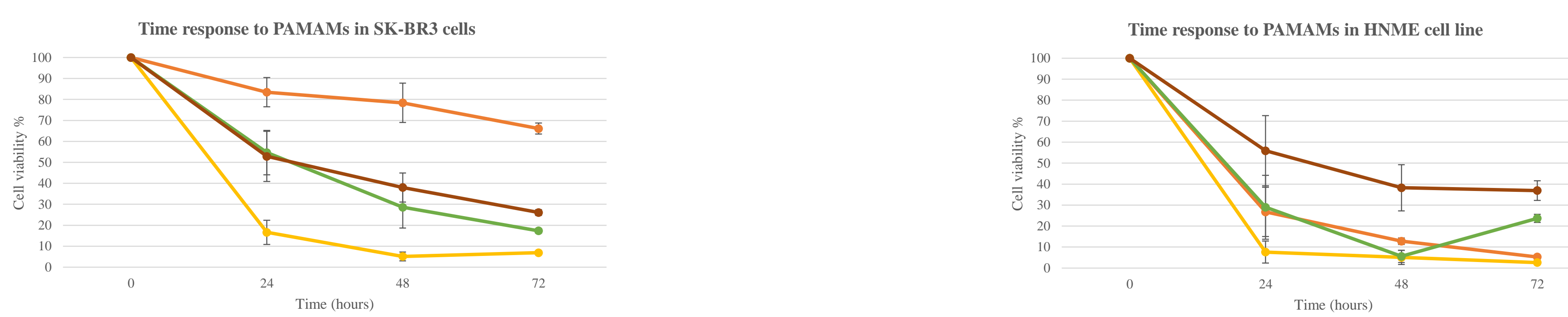

Figure 2: Time-response to the treatment of SK-BR3 and HNME cells with PAMAM dendrimers: $\mathrm{G}_{4} \mathrm{NH}_{2}$ at $10 \mu \mathrm{M}, \mathrm{G}_{6} \mathrm{NH}_{2}$ at $10 \mu \mathrm{M}, \mathrm{G}_{6} \mathrm{OH}$ at $100 \mu \mathrm{M}$, and $\mathrm{G}_{5.5} \mathrm{COOH}$ at $100 \mu \mathrm{M}$.

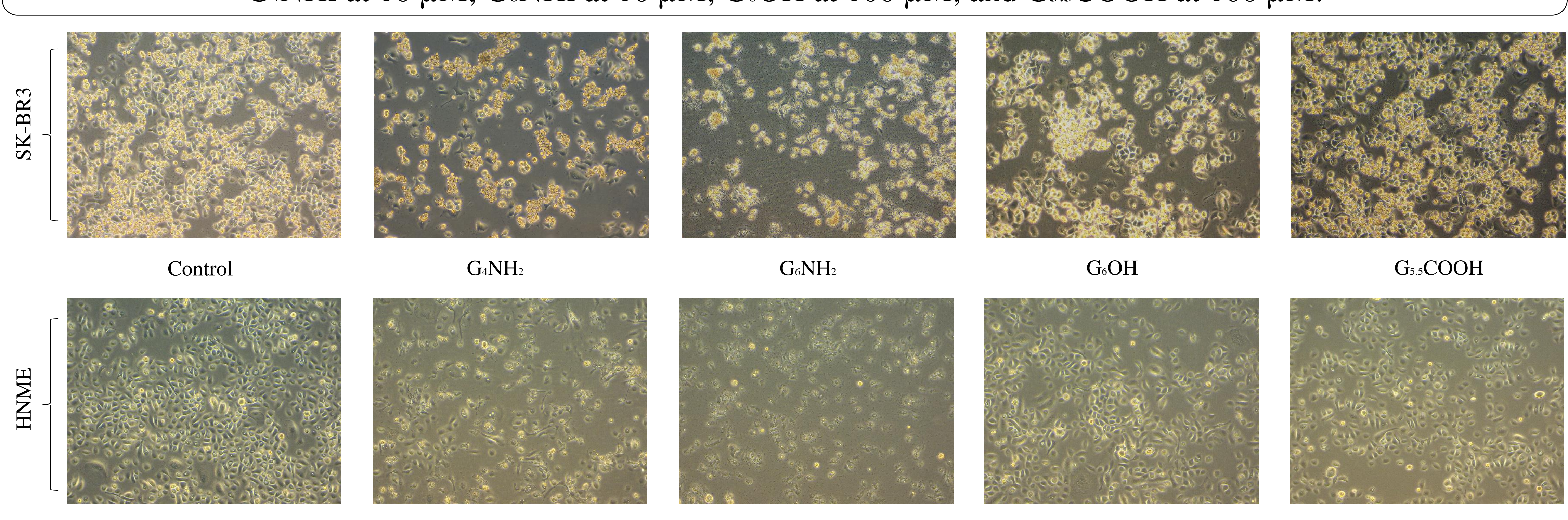

Figure 3: Morphological changes induced by PAMAM dendrimers upon treatment for 48 hours

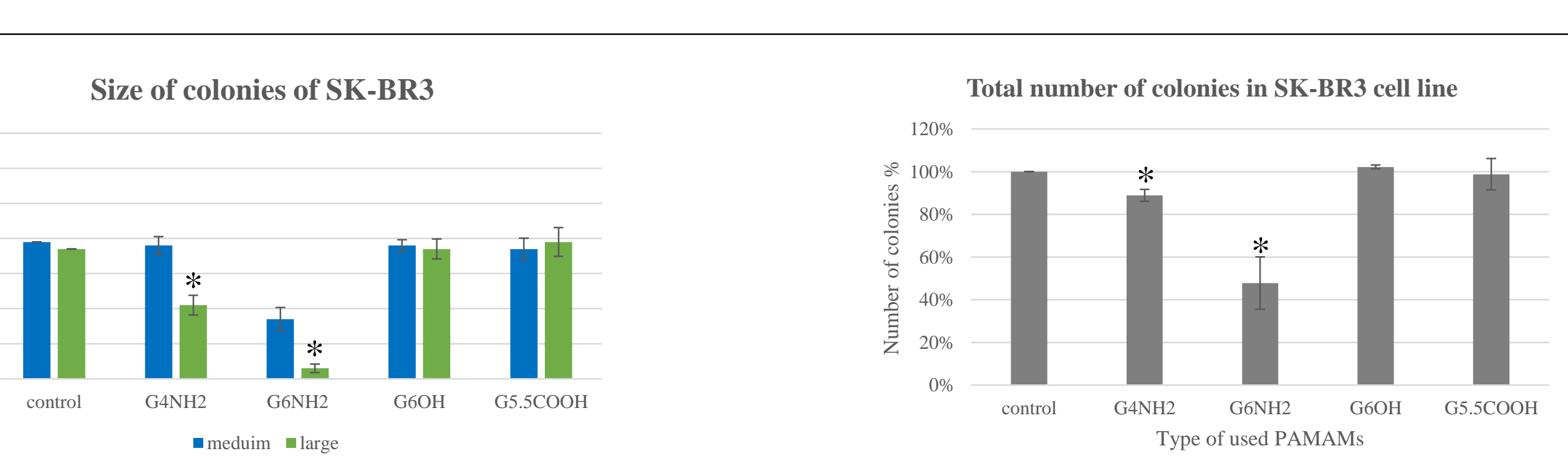

Figure 4: Effect of PAMAM dendrimers on the number and size of SK-BR3 colonies.

\section{Western blot}

- To investigate the underlying mechanisms of action, western blot was used to detect specific proteins of interest.

- Our results revealed that PAMAM dendrimers reduced the expression of erbB2 (HER2) as well as its phosphorylation in SK-BR3 cell line compared to the control.

- In addition, the expression of JNK1/2/3 (cJun N-terminal kinases) was also decreased.

- These results were the most significant in $\mathrm{G}_{6} \mathrm{NH}_{2}$ PAMAMs (P-value $<0.001$ ).

\section{CONCLUSION}

PAMAM dendrimer inhibited the viability of HER 2 positive breast cancer cells in a dose-, time- and generation-dependent manner. They also induced several morphological changes and reduced colony formation in soft agar, particularly amino-terminated PAMAMs. These effects are mediated by decreasing the phosphorylation of erbB2 (HER2) which is overexpressed in this type of cancer. In addition, they reduced the expression of JNK1/2/3 which plays a major role in cancer development and progression. Further studies of other molecular pathways are planned. Our findings may lead to employing cationic PAMAMs in cancer therapy, mainly to add benefit to other anti-tumor compounds either as a carrier or as a combination therapy.

ACKNOWLEDGMENT: This work has been supported by Qatar University Student Grants: QUST-1-CPH-2020-12, QUST-2-CPH-2019-18, QUST-1-CPH-2019-6 